\title{
Malignant Melanocytic Matricoma and Criteria for Malignancy
}

\author{
Colton B. Nielson, Vladimir Vincek ${ }^{*}$ \\ Department of Dermatology, University of Florida College of Medicine, Gainesville, USA \\ Email: *Vincek26@dermatology.med.ufl.edu
}

How to cite this paper: Nielson, C.B. and Vincek, V. (2018) Malignant Melanocytic Matricoma and Criteria for Malignancy. Open Journal of Pathology, 8, 94-100. https://doi.org/10.4236/ojpathology.2018.8 $\underline{3011}$

Received: June 14, 2018

Accepted: July 10, 2018

Published: July 13, 2018

Copyright $\odot 2018$ by authors and Scientific Research Publishing Inc. This work is licensed under the Creative Commons Attribution International License (CC BY 4.0).

http://creativecommons.org/licenses/by/4.0/

\section{cc) (i) Open Access}

\begin{abstract}
Melanocytic matricoma is a very rare adnexal tumor that recapitulates the anagen hair follicle bulb. Few cases of malignant melanocytic matricoma have been reported, thus criteria for malignant potential have not been previously reviewed. We report a case of an 81 year old male that was originally diagnosed as atypical melanocytic matricoma. The site was re-excised with a small focus of residual tumor, but all margins were negative. The re-excision site healed without complication. However, two years after the original biopsy, a new $8 \mathrm{~mm}$ firm nodule appeared at the re-excision site, which was subsequently diagnosed as malignant melanocytic matricoma (MMM). In the following paper we will report a new case of MMM and review potential criteria that could be used in the future to establish malignant potential.
\end{abstract}

\section{Keywords}

Pigmented Malignant Pilomatricoma, Malignant Melanocytic Matricoma, Melanocytic Matrical Carcinoma, Matricoma

\section{Introduction}

Melanocytic matricoma is a rare cutaneous neoplasm that typically presents clinically as a pigmented papule on sun exposed skin in the elderly [1]. Histologically, the tumor is believed to recapitulate the anagen hair follicle bulb. The tumor is usually composed of well-circumscribed solid dermal nodule(s) with a dual population of epithelial matrical and supramatrical cells admixed among darkly pigmented dendritic melanocytes [1] [2]. Within matrical cells, a relatively small foci of shadow cells are present. To date, less than twenty cases of this disease have been reported in the literature [3]. Thus, clinical behavior of the tumor has been difficult to predict. In recent years, seven cases of a malignant variant of melanocytic matricoma have been reported [4] [5] [6] [7] [8]. 
This entity is important to recognize as melanocytic matrical carcinoma can mimic melanoma when melanocytic proliferations or melanin pigment are prominent [8]. Here, we report an additional case of malignant melanocytic matricoma and discuss criteria that might be useful to predict malignant potential.

\section{Case Report}

\subsection{Clinical Presentation}

An 81-year old white male with history of multiple non-melanoma skin cancers presented for a bothersome lesion on the posterior left forearm. Clinical suspicion was high for basal cell carcinoma and a shave biopsy was obtained. The biopsy was reviewed by a private practice dermatopathologist and was diagnosed as atypical melanocytic matricoma with positive deep margins. The site was re-excised with a small focus of remaining tumor, but with negative margins. Two years after the original biopsy, an $8 \mathrm{~mm}$ firm nodule appeared at the re-excision site. The new nodule was biopsied and reviewed at the University of Florida and determined to be malignant melanocytic matricoma. Histopathology of the original biopsy was compared with histopathology of the recurrent nodule. Re-excision with negative margins was performed and the re-excision site healed well. Unfortunately, the patient died several months later due to heart failure.

\subsection{Histopathologic Findings}

Microscopically, the original shave biopsy demonstrated a dermal tumor with the largest diameter measuring $2 \mathrm{~mm}$, in addition to several smaller nodules (Figure 1). The tumor did not demonstrate epidermal connection. Furthermore, neither glandular nor ductal differentiation were identified. The tumor was made of mostly basaloid epitheliod matrical cells with nuclear atypia, small foci of ghost cells, and scattered pigmented cells forming focally small aggregates. Focal necrosis and calcinosis of tumor cells was observed. Multiple mitoses were present. The epitheliod cells were cytokeratin AE1/AE3 and cytokeratin 5/6 positive and pigmented cells were Melan-A, S-100, and HMB 45 positive.

Review of the recurrent nodule at the original biopsy site demonstrated a deep and irregular dermal nodule measuring $3 \mathrm{~mm}$ in diameter (Figure 2). Although two cell components were present, similar to the original biopsy, the recurrent nodule had significantly increased numbers of melanocytic cells (Melan-A, S-100, HMB45 positive). In fact these cells were outnumbering the epitheliod cytokeratin AE1/AE1 positive cells (Figure 3(a), Figure 3(b)). The number of proliferating cells (KI-67 marker) were significantly increased (Figure 3(c)), particularly among melanocytic cells. Necrosis and increased pigment were more prominent in the recurrent nodule.

\section{Discussion}

Pilomatricoma and matricoma are described as benign neoplasms consisting of 

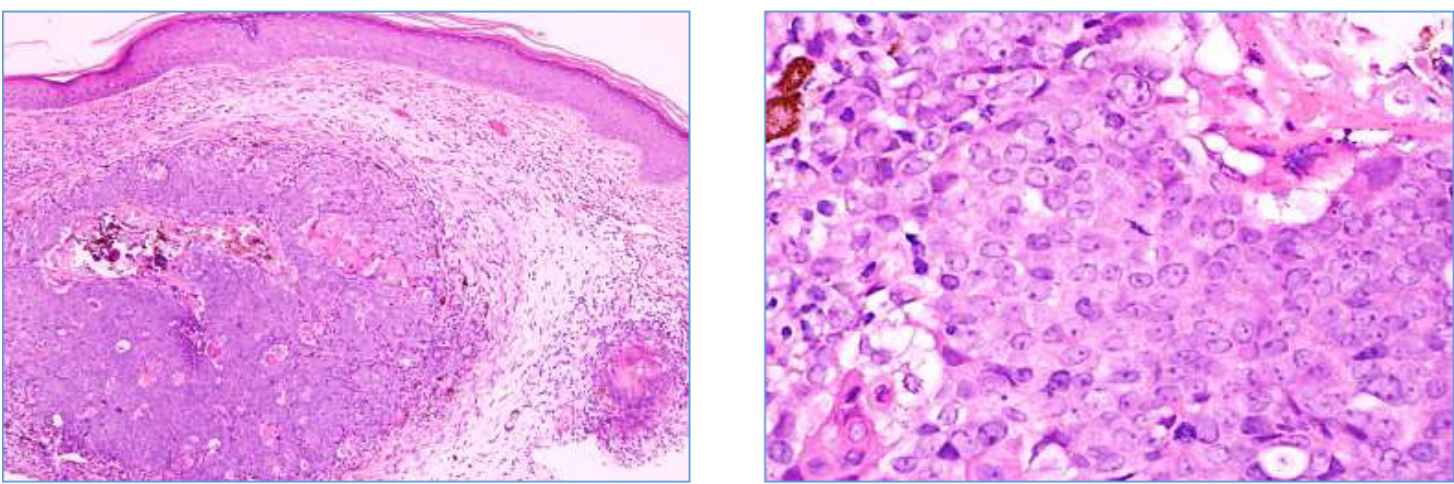

Figure 1. Low power $(40 x)$ and high power $(200 x)$ of the original dermal lesion.
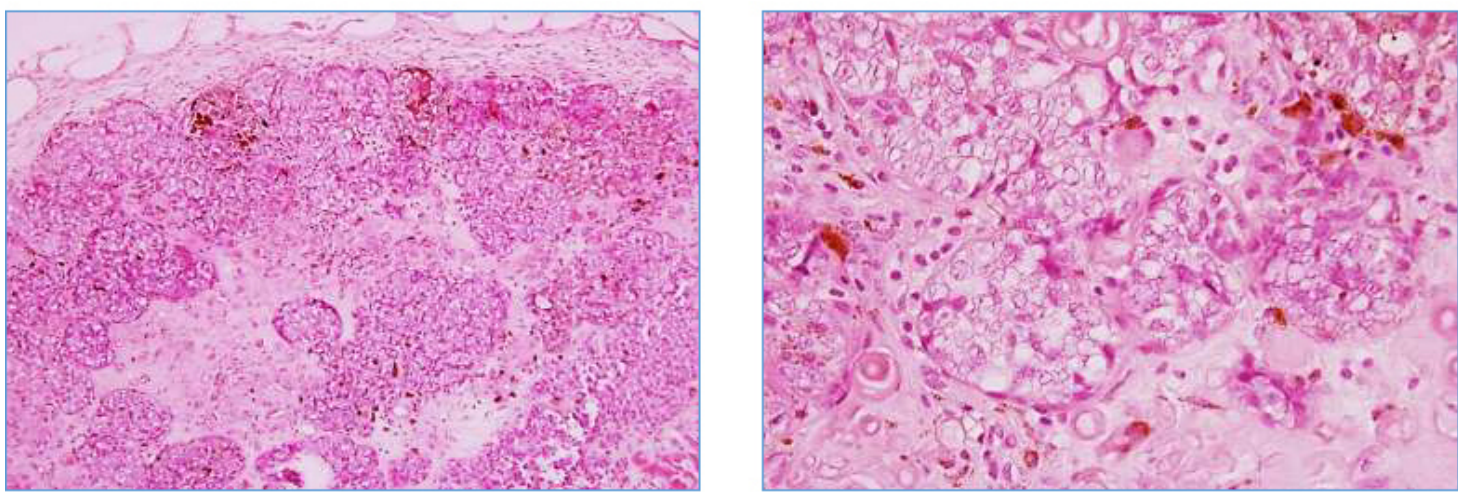

Figure 2. Low power $(40 \times)$ and high power $(200 \times)$ of the recurrent subcutaneous lesion.
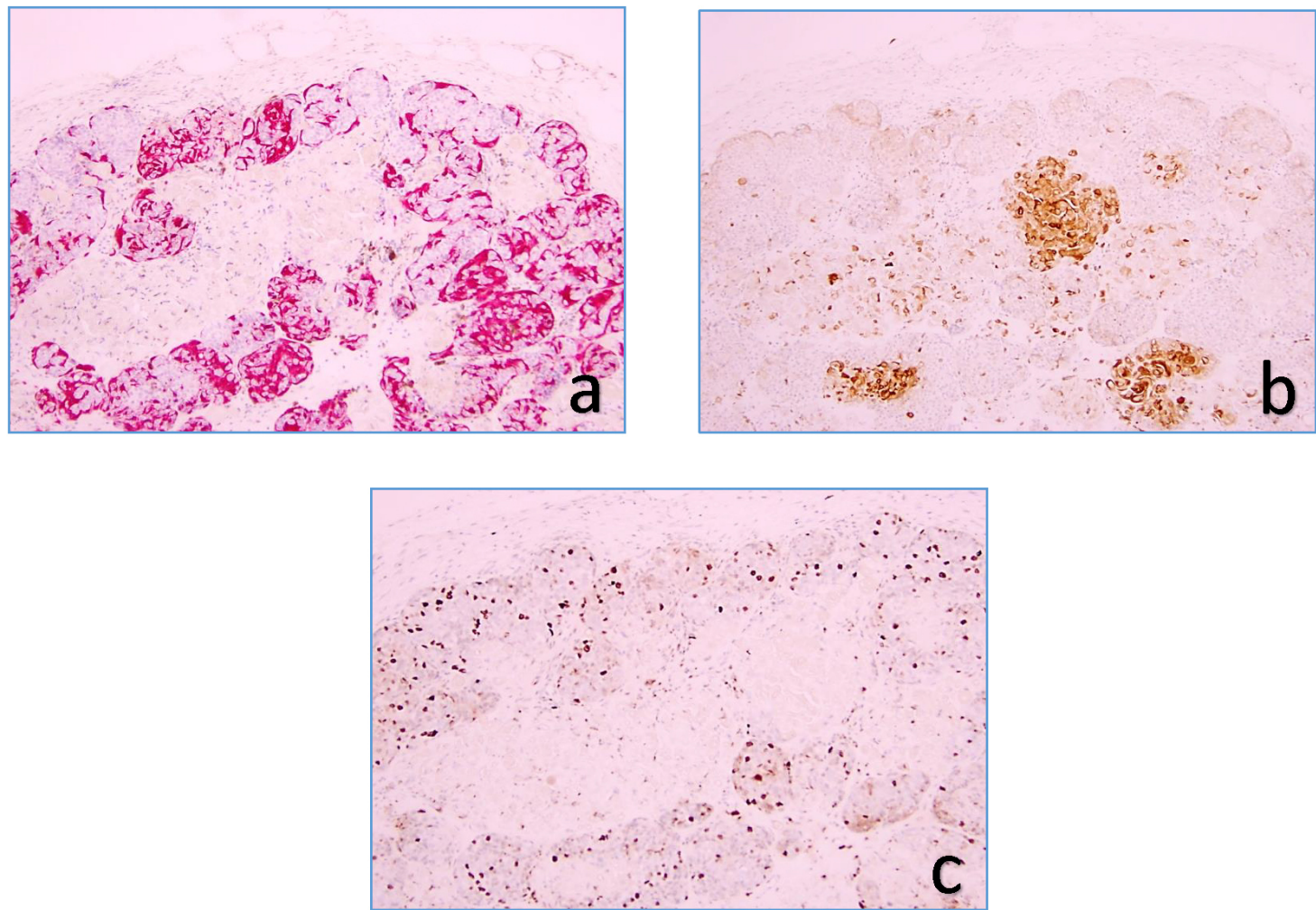

Figure 3. Melan-A stain (red) outlines melanocytes (a), cytokeratin AE1/AE3 stain (brown) outlines epithelial elements (b), and KI-67 stain (brown) detects proliferating cells (40×). 
the same basic cellular components of matrical, supramatrical, and shadow or ghost cells, but with different architectural patterns [9]. Pilomatricomas are mostly circumscribed, cystic lesions that are present in the dermis and subcutis. In comparison, matricomas are composed of dermal lesions of small aggregates that can be cystic, solid and cystic, or solid [9]. In 1999, a new entity termed melanocytic matricoma was described [1]. Melanocytic matricomas have the same cellular elements as pilomatricoma and matricoma, but with an additional admixture of heavily pigmented melanocytes. Melanocytic matricomas present architecturally as solid dermal nodules without calcification of ghost cells, epidermal connection, or cyst formation. Some authors have accepted this diagnosis as a new entity [10] [11] [12], while others consider this diagnosis a pigmented variant of matricoma [13] [14]. Recent descriptions of melanocytic matricomas with calcifications, granulomatous response, and an epidermal connection [10] [15] suggest that melanocytic matricomas represent a pigmented variant of matricoma. However, the number of previously described cases in the literature are less than twenty [3] [16] [17] [18], and therefore, a final judgment should be made when more cases are described.

Pilomatricoma, matricoma, and melanocytic matricoma are considered benign adnexal neoplasms [1] [9]. However, cases of malignant melanocytic matricomas have been described [4] [5] [6] [7] [8], in addition to several cases with atypical histological attributes [19] [20] [21]. MMM appears to present in a similar clinical picture to melanocytic matricoma, most often occurring on sun damaged skin (face) in elderly males (avg age 75) [7] [8] [9] [10].

The histological differential diagnosis of MMM includes: trichoblastoma, pigmented basal cell carcinoma, basal cell carcinoma with matrical differentiation, and most importantly, malignant melanoma [7] [8] [9] [10]. In MMM, atypical matrical cells could be mistaken for atypical melanocytes. However, the degree of pleomorphism in malignant melanoma should be utilized as a distinguishing factor [7] [8]. Furthermore, malignant melanoma usually originates at the dermal-epidermal junction and invades the dermis. On the other hand, MMM is typically a dermal process.

As the number of previously described melanocytic matricomas are very small, the criteria to determine malignant potential has not been elucidated. We have compared features of all reported MMM's, including our own (Table 1). At the cellular level, benign and malignant melanocytic matricoma have a similar number of basaloid and ghost cells. Surprisingly, the number of mitoses was high in the epithelial component of malignant matricomas but was also high in many cases of benign melanocytic matricoma [1]. The major difference between benign and malignant matricomas was at the architectural levels. Whereas benign cases were made of well-defined nodules, all malignant cases were architecturally ill-defined, with multiple nodules and infiltrating or pushing borders. Also, focal necrosis was seen in all but one case of MMM and not in the benign cases. In addition, more than half of malignant lesions were ulcerated. 
Table 1. Summary of malignant melanocytic matricomas reported in literature.

\begin{tabular}{ccccccc}
\hline Report & Age/Sex/Location & Follow up & Necrosis & Silhouette & Ulceration & Mitoses \\
\hline Monteagudo [4] & 48/M/neck & Recurrence after 2 years & Absent & Ill-defined, infiltrative & Ulcerated & $4 / 10 \mathrm{HPF}$ \\
Monteagudo [4] & 77/M/chest & Unavailable & Present & Ill-defined, infiltrative & Ulcerated & $34 / 10 \mathrm{HPF}$ \\
Jani [5] & 77/M/nose & Free of disease after 2 months & Present & Ill-defined, pushing & Ulcerated & Numerous \\
Limarporn [6] & $81 / \mathrm{M} /$ not reported & Unavailable & Present & Not reported & Ulcerated & $20 / 10 \mathrm{HPF}$ \\
Ardakani [7] & $72 /$ F/elbow & Free of disease after 6 months & Present & Ill-defined, pushing & Absent & $30 / 10 \mathrm{HPF}$ \\
Ardakani [7] & 78/M/face & Free of disease after 6 months & Present & Ill-defined, pushing & Absent & $50 / 10 \mathrm{HPF}$ \\
Ji [8] & 80/M/face & Free of disease after 1 year & Present & Ill-defined, infiltrative & Ulcerated & $>10 / \mathrm{HPF}$ \\
present report & $81 / \mathrm{M} /$ forearm & Recurrence after 2 years & Present & Ill-defined, infiltrative & Absent & $5 / 10 \mathrm{HPF}$ \\
\hline
\end{tabular}

\section{Conclusion}

In conclusion, MMM is a very rare tumor but with characteristic cytological and architectural features. Recurrence and metastasis are two definite criteria for malignancy. Multinodular infiltrative growth, tumor necrosis, and ulceration may suggest more aggressive behavior. In contrasts to previous reports, it appears that an increased number of mitoses are not a reliable predictor of behavior. Pathologists should be aware of this entity when dealing with a biphasic basaloid/melanocytic lesion to avoid misdiagnosis [8]. The clinical behavior of these tumors is yet to be fully elucidated, with very few cases reported and limited follow-up. Therefore, complete excision with clear margins and close follow-up of patients are recommended. Reporting of future cases, including clinical follow-up, will help delineate predictors of biological behavior in this tumor.

\section{Conflicts of Interest and Source of Funding}

None to declare for all authors.

\section{References}

[1] Carlson, J.A., Healy K., Slominski, A. and Mihm, M. (1999) Melanocytic Matricoma: A Report of Two Cases of a New Entity. American Journal of Dermatopathology, 21, 344-349. https://doi.org/10.1097/00000372-199908000-00006

[2] Carlson, J.A., Slominski, A. and Mihm, M. (2003) What Are the Clinicopathologic Features of Matricoma? American Journal of Dermatopathology, 25, 446-447. https://doi.org/10.1097/00000372-200310000-00015

[3] Pagliarello C., Stanganelli I., Ricci R., Feliciani C. and Di Nuzzo S. (2017) A Pinkish-Blue Exophytic Nodule on the Arm of an Elderly Man: Melanocytic Matricoma. Acta Dermatologica Venereologica, 97, 1261-1262. https://doi.org/10.2340/00015555-2740

[4] Monteagudo, C., Fernandez-Figueras, M., San Juan, J., Lopez, D. and Carda, C. (2003) Matrical Carcinoma with Prominent Melanocytic Hyperplasia (Malignant Melanocytic Matricoma?). A Report of Two Cases. American Journal of Dermatopathology, 25, 485-489. https://doi.org/10.1097/00000372-200312000-00005 
[5] Jani, P., Chetty, R. and Ghazarian D.M. (2008) An Unusual Composite Pilomatrix Carcinoma with Intralesional Melanocytes: Differential Diagnosis, Immunohistochemical Evaluation, and Review of the Literature. American Journal of Dermatopathology, 39, 174-177. https://doi.org/10.1097/DAD.0b013e318165b8fe

[6] Limarporn, L., Lourie, R., Pool, L. and Wong, D. (2012) Malignant Melanocytic Matricoma: A Case Report and Review of the Literature. Pathology, 44, S87. https://doi.org/10.1016/S0031-3025(16)32844-6

[7] Ardakani, N.M., Palmer, D.L.G. and Wood, B.A. (2016) Malignant Melanocytic Matricoma: A Report of 2 Cases and Review of the Literature. American Journal of Dermatopathology, 38, 33-38. https://doi.org/10.1097/DAD.0000000000000329

[8] Ji, C., Zhang, Y., Hler, P. and Guo, Y. (2017) Melanocytic Matrical Carcinoma Mimicking Melanoma. American Journal of Dermatopathology, 39, 903-906. https://doi.org/10.1097/DAD.0000000000000771

[9] Ackerman, A.B., De Viragh, P.A. and Chongchitnant, N. (1993) Pilomatricoma and Matricoma. In: Neoplasms with Follicular Differentiation, Lea\&Febinger, Philadelphia, PA, 475-506.

[10] Islam, M.N., Bhattacharyya, I., Proper, S.A., Glanz, S.M., Vega, J.M. and Hassanein, A.M. (2007) Melanocytic Matricoma: A Distinctive Clinicopathologic Entity. Dermatological Surgery, 33, 857-863. https://doi.org/10.1097/00042728-200707000-00015

[11] Cartaginese, F. and Sidoni, A. (2010) Melanocytic Matricoma. Report of a Further Case with Clinicopathological and Immunohistochemical Findings, Differential Diagnosis and Review of Literature. Histology and Histopathology, 25, 713-717.

[12] Rizzardi, C., Brollo, A., Colonna, A., Brutto, R.L. and Melato, M. (2002) A Tumor with Composite Pilo-Folliculosebaceous Differentiation Harboring a Recently Described New Entity-Melanocytic Matricoma. American Journal of Dermatopathology, 24, 493-497. https://doi.org/10.1097/00000372-200212000-00007

[13] Resnick, K.S. (2003) Is Melanocytic Matricoma a Bona Fide Entity or Is It Just One Type of Matricoma? American Journal of Dermatopathology, 25, 166-167. https://doi.org/10.1097/00000372-200304000-00014

[14] Rizzardi, C, and Melato, M. (2003) Splitting Hairs in Hair Matrix Tumors! Author's Reply. American Journal of Dermatopathology, 25, 166-167. https://doi.org/10.1097/00000372-200304000-00015

[15] Tallon, B. and Cerroni, L. (2010) Where Pigmented Pilomatricoma and Melanocytic Matricoma Collide? American Journal of Dermatopathology, 32, 769-773. https://doi.org/10.1097/DAD.0b013e3181d88d15

[16] Nikaido, M., Yamada, M., Konno, T., Hara, K., Yamamoto, T. and Suzuki, T. (2013) Agminated Pigmented Matricoma: A Case of a Unique Tumor with a Multifocal Appearance Composed of Neoplastic Matrical Cells with a Significant Component of Melanocytes. Journal of Cutaneous Pathology, 40, 823-828. https://doi.org/10.1111/cup.12185

[17] Tanboon,J., Manonukul, J. and Pattanaprichakul, P. (2014) Melanocytic Matricoma: Two Cases of a Rare Entity in Woman. Journal of Cutaneous Pathology, 41, 775-782. https://doi.org/10.1111/cup.12345

[18] Battistella, M., Carlson, J.A., Osio, A., Langbein, L. and Cribier, B. (2014) Skin Tumors with Matrical Differentiation: Lessons from Hair Keratins, Beta-Catenin and PHLDA-1 Expression. Journal of Cutaneous Pathology, 41, 427-436.

https://doi.org/10.1111/cup.12313 
[19] Zussman, J., Sheth, S., Ra, S.H. and Binder, S.W. (2011) Melanocytic Matricoma with Melanocytic Atypia: Report of a Unique Case and Review of the Literature. American Journal of Dermatopathology, 33, 508-512. https://doi.org/10.1097/DAD.0b013e3181ec711c

[20] Rodic, N., Taube, J.M., Manson, P., Patel, M., Patterson, J.W. and Erdag, G. (2013) Locally Invasive Dermal Squamomelanocytic Tumor with Matrical Differentiation: A Peculiar Case with Review of the Literature. American Journal of Dermatopathology, 35, 72-76. https://doi.org/10.1097/DAD.0b013e31827d989c

[21] Winslow, C.Y., Camacho, I. and Nousari, C.H. (2017) Melanocytic Matricoma with Consumption of the Epidermis: An Atypical Histologic Attribute or a Malignant Variant? American Journal of Dermatopathology, 39, 907-909.

https://doi.org/10.1097/DAD.0000000000000803 